\section{Feasibility assessment of distributed generation systems in Sagar Island, West Bengal, India}

\author{
Partha Sarothi Sikder and Nitai Pal* \\ Department of Electrical Engineering, Indian Institute of Technology \\ (Indian School of Mines), Dhanbad 826 004, India
}

Energy is one of the basic needs of socio-economic development of an area. The conventional method of electricity generation and grid-connected transmission and distribution system is expensive for the remote rural areas of India, resulting in lower per capita energy consumption. Grid connectivity or establishing new power plants using conventional energy sources is more difficult and expensive in the islands. The depletion of conventional energy sources is also another reason to explore alternative energy sources. Regardless of the cost and depletion of conventional energy sources, environmental issues are of greater concern on the islands. The pollution due to conventional energy sources destroys the biodiversity and ecological health of an island. The aim of the present study is to examine the distributed generation system using different renewable energy sources from the available meteorological data of the largest island in the Sundarbans deltaic complex, West Bengal, India, viz. Sagar Island. The vast number of renewable energy sources available in this island have been studied and the possibility of electricity generation is discussed. Moreover, the possible per unit cost is also estimated using levelized cost of energy.

Keywords: Conventional energy sources, distributed generation system, islands, renewable energy.

AT present, energy utilization is one of the prime indicators of sustainable development. India is a developing country where the generated electrical energy is approximately $329,205 \mathrm{MW}$ with a $0.8 \%$ energy deficit ${ }^{1}$. Due to rising population and increasing load demand, the energy deficit is difficult to compensate. In India, the per capita energy consumption per person is around $1075 \mathrm{kWh}$, which is below the world average and very much lower than that of developed countries. This indicates the poor sustainable development of the country. The problem is related to energy deficit mainly faced by the remote rural areas due to difficult and cost-effective grid connectivity which minimizes the sustainable development. In India, $67 \%$ of the energy is produced from fossil fuels and it is difficult to increase the generation capacity due to depletion to compensate future energy demands ${ }^{2}$. At present, environmental pollution is a prime concern. All the primary energy sources cause damage to our environment,

*For correspondence. (e-mail: nitai_pal@rediffmail.com) leading to a new era for generating electricity from renewable energy sources to compensate future energy demands and initiate sustainable development.

The problem related to energy deficit is significant in the remote rural areas and islands where grid connectivity is difficult due to topographical constraints. The Indian islands face great difficulty to access reliable electricity. Environmental issues are more predominant in Sagar Island, West Bengal, India where contamination of the environment destroys biodiversity and ecological balance. Nowadays, to electrify a distant land from the main land, the distributed generation policy has been introduced by the Government and International Corporations. Generally, in distributed generation, the renewable energy system is used to reduce the environmental pollution. Thus renewable energy resource management is much essential to generate pollution-free electricity for sustainable development of the island.

Sagar Island is located in the Sundarban region, which is world's largest delta formed by the rivers Ganga (Hugli in this region), Brahmaputra and Meghna. About 40,000 families inhabit 47 villages of Sagar Island spread over 504 sq. $\mathrm{km}$ area. Due to premature reclaim, parts of the Island remain $3 \mathrm{~m}$ below sea level. Hence environmental imbalance is dangerous to the very existence of Sagar Island $^{3}$. Most of the places in Sundarban area are separated from the mainland by rivers and creeks which make the grid-connected electricity supply system difficult. Sagar Island, like other parts of the Sundarban, is characterized by mangrove swamps, waterways and small rivers, isolated from the mainland by the Indian Ocean and the Hugli River, which restrains the grid connectivity and suppresses sustainable development ${ }^{4}$. Due to insufficient electrical energy, sustainable development of the island is not adequate and future development is also difficult. Due to lack of electricity, majority of families depend upon kerosene lamps for emergency lighting purposes.

At present, a lot of research is being done on distributed generation systems worldwide. Some researchers studied the different renewable energy sources and their impact on the environment for future demand ${ }^{5}$. Some studies mainly focused on the optimization of renewable energy sources for a predicted load consumed in a particular area for sustainable development $t^{6,7}$. Studies have also optimized the minimum cost for renewable energy sources combined with diesel generator to compensate a particular load ${ }^{8-10}$. In Sagar Island, research has been concentrated on solar energy and biomass energy to generate electricity ${ }^{11-14}$. The hybrid generation system with diesel generator has also been studied here with details available on the technological development and practical implementation, data analysis and optimization ${ }^{15}$. However, the feasibility of electricity generation using tidal and ocean energy sources has not been examined. In this present study, the different topologies of electricity generation in Sagar Island using different renewable energy 


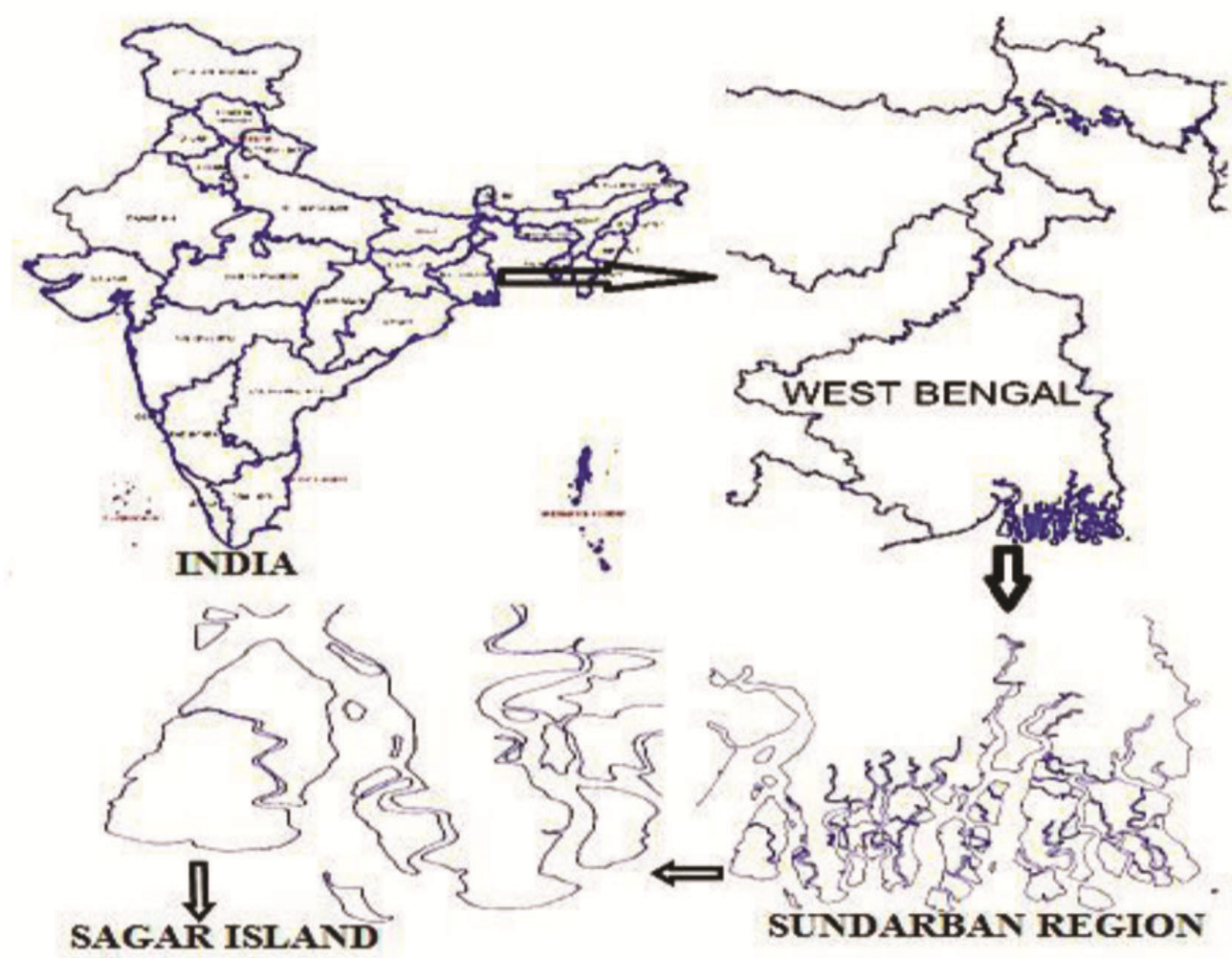

Figure 1. Location of Sagar Island in the Sundarban area, West Bengal, India ${ }^{16}$.

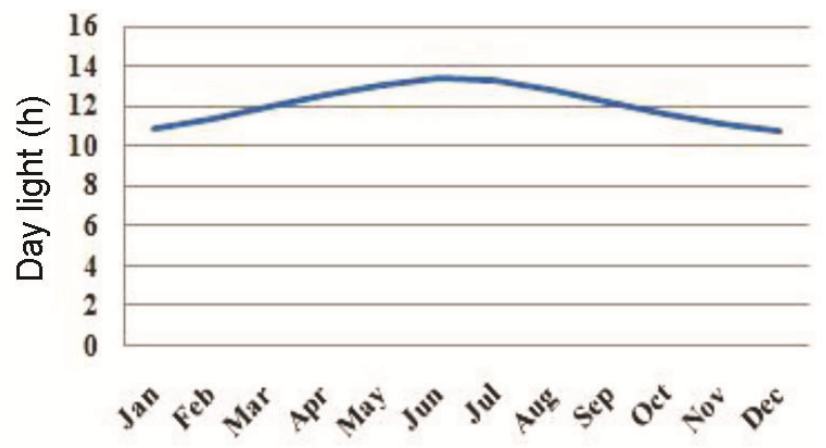

Figure 2. Average daylight hour on the Sagar Island during different months of the year.

sources have been studied with comparative cost analysis. The possible energy mix to construct a hybrid system to increase reliability and generation capacity without increasing the storage devices is also discussed, without compromising the environmental effect. The present study will help initiate further research for new energy generation technology in Sagar Island, where a wide variety of renewable energy sources is available.

Figure 1 shows the location of Sagar Island in Sundarban area ${ }^{16}$. The Island is located between the Tropic of Cancer and the equator, where adequate solar energy is available throughout the day ${ }^{17}$. Availability of solar energy and barren coastal area indicate the availability of wind energy. There are hydel energy sources based on the
Hugli River (local name - Muri Ganga) to generate electricity. The other renewable sources are biomass, tidal energy and blue energy.

Solar energy is one of the promising energy resources in the world due to its availability, noiseless operation and less maintenance during the generation of electrical ener$\mathrm{gy}^{18}$. According to the NASA surface metrology in Sagar Island, the sun provides promising solar energy with an average $13.6 \mathrm{~h}$ (solar hour) round the year (Figure 2$)^{19}$.

Figure 3 shows the average monthly solar irradiance of Sagar Island. During different months, the solar irradiance and solar hour are adequate to generate energy using solar photovoltaic (SPV) as well as concentrating solar thermal (CST) technology or a combination of both. The only difficulty related to solar energy is less energy density compared to other sources. The efficiency to convert solar energy is around $17 \%$ for CST and $15 \%$ for SPV technology. Compared to CST, SPV system is more acceptable due to the less maintenance during operation. Due to less energy density, the area required to establish the solar power plant is very large. The other difficulty to utilize solar energy to generate electricity depends on the seasonal variation of clear-sky irradiance level. During monsoon, solar irradiance is hardly available in Sagar Island. In Sagar Island, the maximum estimated numbers of sun days is 8.75 . It requires large numbers of batteries to store the generated energy. The use of huge number of batteries reduces the flexibility and increases the cost of the system. It also occupies more space. 


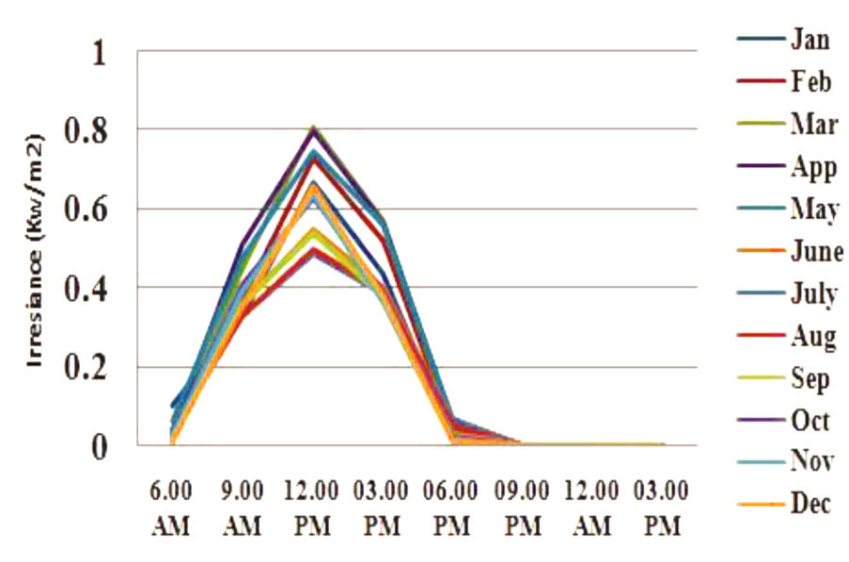

Figure 3. Monthly solar irradiance variation during different months in Sagar Island.

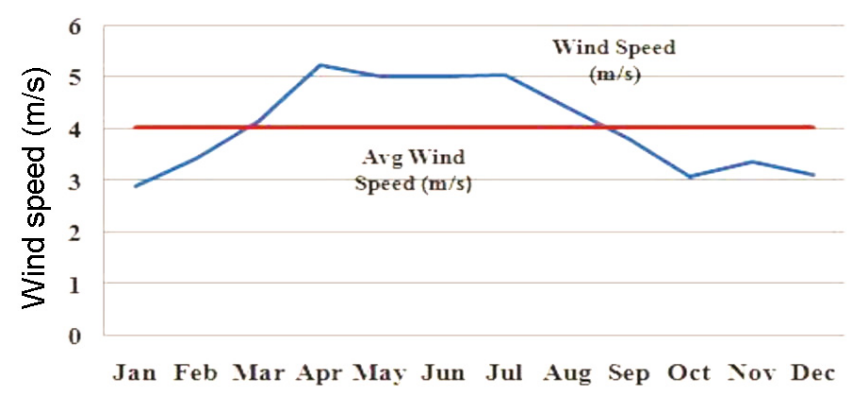

Figure 4. Monthly wind speed variations in Sagar Island.

A wind turbine attached to a generator converts kinetic energy of wind into electricity. Normally $3-15 \mathrm{~m} / \mathrm{s}$ is the optimum wind speed to generate electricity using wind energy. At present, due to developed technology and materials science built the lower speed wind turbine to generate electricity ${ }^{20}$.

The wind is a by-product of solar energy. Approximately $2 \%$ of solar energy reaching the earth is converted into wind energy. Sagar Island provides low but moderate wind speeds (Figure 4$)^{19}$. The island has plenty of barren land in the coastal areas resulting in uninterrupted wind flow. There is also adequate space for construction of a tower and other accessories to generate electrical energy from wind energy.

The potential energy of water is converted into electricity using turbine generator set in the range of a few watts to kilowatts, this is called small-scale hydro-power. The system is based on run-of-river schemes or implemented in existing water infrastructure. The small-scale hydropower plant is normally installed in the hilly areas where the water speed is very high. The total small-scale hydro energy is essential and beneficial in terms of low-cost electricity, quick start and no environmental impact. The Sagar Island encircles the Hugli River, but due to flat geographical surface the water speed does not fulfil the requirement to generate electricity.
The Sagar Island is surrounded by natural forests and barren land covered with weeds, which are considered as biomass. As the main occupation in the Island is cultivation, the agricultural by-product is also considered as biomass. Rice husk, crop residue, jute stick, wood, animal waste, municipal waste, etc. all are available in Sagar Island. To extract energy from biomass, normally biomass is burnt in a boiler to generate electricity using a gas turbine. Due to the burning of biomass, some pollutant gases are generated during the generation of electricity, but as the biomass resources regenerate within a few years it is considered as a renewable energy source. Using recent technology biomass is converted to biofuel and directly utilized for transportation and pumping operation. Using the developed technology, production of hydrogen energy from biomass is also possible. The produced hydrogen is utilized in vehicles or to generate electricity using fuel cells. The direct estimation of biofuel or biomass is not possible because it is directly related to the field survey and other variables ${ }^{21-22}$.

The available forms of energy from the ocean to generate electricity are tidal energy, wave energy, ocean thermal energy conversion (OTEC) and salinity gradient. Due to gravitational force by the sun and the moon, the level of the earth's surface water changes in a cyclic manner, which is known as tidal energy ${ }^{23}$. To convert tidal energy into electricity, tidal-barrages technology and tidalcurrent technology are used. In the former case, a dam is built to store water during high tides and this stored water is then discharged through a water turbine during ebb tides. The attached generator generates electricity by converting the potential energy of water due to tides. In the latter case, the water current due to tides is utilized to generate electricity. The kinetic energy of the water stream is converted to electricity using an underwater turbine attached to the generator, similar to the wind energy conversion system. The Sagar Island has a higher value of tide ranges around $6 \mathrm{~m}$ (maximum) to $1.5 \mathrm{~m}$ (minimum, Figure 5) which indicates the prospects of generation of electrical energy from tidal energy sources $^{24}$.

The wave energy is a by-product of solar and wind energy. The other factors affecting the wave energy is the distance of open water over which the wind blows, width of the area affected by the wind, duration of wind blow and water depth ${ }^{25}$. The Sagar Island, is located at the Bay of Bengal (BoB) covering a large coastal area, and massive solar energy around the year with maximum solar hour around $13.6 \mathrm{~h}$. Due to geographical location, Sagar Island has a huge potential of wave energy which is estimated based on data provided by a station wave energy estimation station 23,223 of $\mathrm{BoB}$ near Sagar Island (Figure 6$)^{26}$. The data obtained from the wave station indicate the huge potential of wave energy to generate electricity, but the disadvantages are costly equipment and advanced technology. 
In OTEC, the temperature difference between sea surface water and deep water can be harnessed to generate electricity ${ }^{27,28}$. The surface water of the ocean traps heat energy from the sun. This trapped energy is used by the working fluid using a heat exchanger. The working fluid evaporates easily by the trapped energy and provides kinetic energy to the turbine. The condensation of the working fluid is done by pumping cold water from the deep ocean. Due to the availability of solar energy, the Sagar Island has a huge difference in temperature from the surface of the ocean to the deep water. Normally a $20^{\circ} \mathrm{C}$ difference in temperature is optimum for the OTEC process, which is available in the Sagar Island. Figure 7

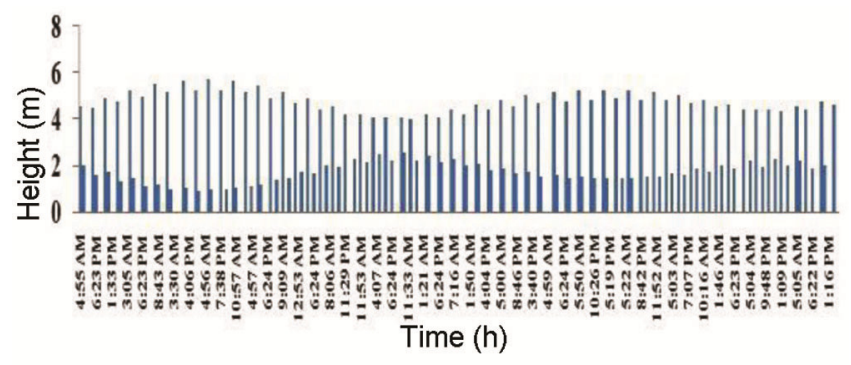

Figure 5. Monthly water height variation in Sagar Island due to tider.
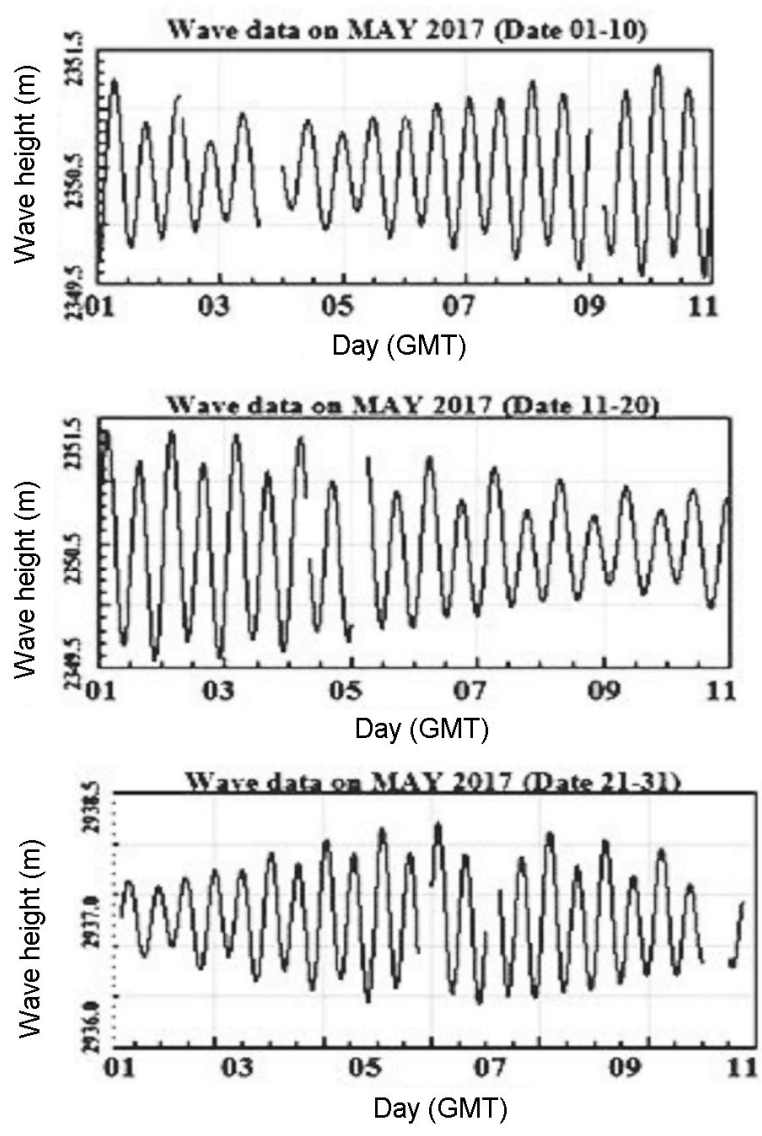

Figure 6. Wave energy in the Indian Ocean near Sagar Island ${ }^{26}$. shows the temperature difference between the surface and deep water. The advanced technology and costly apparatus are barriers to generate electricity using this process.

The salinity difference between freshwater and ocean water has a huge potential to generate electricity. This is called the salinity energy or blue energy ${ }^{29}$. Using advanced membrane science and technology, the blue energy is converted to electricity. There are two methods of harvesting energy from the salinity differencepressure-retarded osmosis (PRO) and reverse electrodialysis (RED). In the former process, the pressure difference between river water and seawater is about $23 \mathrm{~atm}$ under ordinary conditions, equivalent to the hydrostatic head of $231 \mathrm{~m}$ dam. In this process, semi-permeable membranes are utilized to transfer static energy freshwater to the high-concentration draw solution (seawater or brine). The high-pressure seawater extracts more energy from the freshwater than that utilized to rotate the turbine attached to the generator. This produces electrical energy like the hydroelectric generation plant.

In the latter process, seawater and freshwater are pumped into arrays or stacks of membranes with alternating anion-exchange and cation-exchange membranes. The salt water or brine (draw solution) and freshwater (low concentration solution) pass through a semi-permeable membrane with an applied hydraulic pressure. The ion selectivity of the membrane due to the concentration difference between the salt water and fresh water directly produces electrical energy. The difference in electrochemical potential due to movement of ions is converted to an electrical current in the stack.

The Sagar Island is located at the mouth of the Indian Ocean, where the Hugli River, meets the Ocean. Hence the island has a huge prospect of generation of electricity using blue energy. The only difficulties are technological development and high cost.

The feasibility study of generation of electricity is incomplete without considering the cost analysis. To calculate the per unit generation cost of the different power supply systems possible in Sagar Island the levelized cost of electricity (LCOE) method is applied and compared with the diesel-based power supply system.

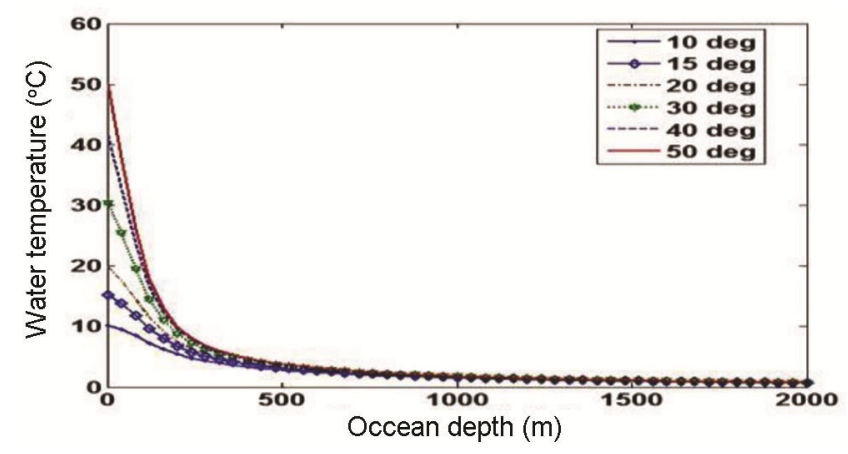

Figure 7. Variation of temperature depth surface with water depth. CURRENT SCIENCE, VOL. 116, NO. 8, 25 APRIL 2019 


\section{RESEARCH COMMUNICATIONS}

Table 1. Calculated per unit generation cost for the different distributed generation systems ${ }^{32}$

\begin{tabular}{lcccc}
\hline Technology & $\begin{array}{c}\text { Overnight cost } \\
\text { (US\$/100 kW) }\end{array}$ & $\begin{array}{c}\text { Fixed operation and } \\
\text { maintenance cost }(\%)\end{array}$ & $\begin{array}{c}\text { Expected } \\
\text { lifetime (year) }\end{array}$ & $\begin{array}{c}\text { Per unit generation } \\
\text { cost (US\$/kWh) }\end{array}$ \\
\hline Diesel & 30,000 & 15 & 5 & 0.2351 \\
Solar PV & 264,400 & 5 & 25 & 0.2783 \\
Solar thermal & 345,900 & 15 & 25 & 0.5358 \\
Onshore wind & 187,700 & 5 & 25 & 0.1567 \\
Offshore wind & 395,300 & 15 & 25 & 0.5073 \\
Biomass & 216,850 & 15 & 30 & 0.1242 \\
Tidal & 261,100 & 15 & 20 & 0.5117 \\
Wave & 378,100 & 5 & 20 & 0.6671 \\
Battery & 281,300 & 15 & 5 & 0.2437 \\
\hline
\end{tabular}

Equation (1) shows the LCOE to estimate generation cost of individual power supply systems ${ }^{30,31}$.

\section{$\mathrm{LCOE}=$ Annual fixed cost per unit}

+ annual variable cost per unit + fuel cost per unit.

To calculate annual fixed cost, the capital recovery factor (CRF) should be multiplied by the overnight generation cost per unit for different power supply systems. Equation (2) shows the mathematical equation of CRF.

$$
\mathrm{CRF}=\frac{r(1-r)^{i}}{(1-r)^{-i}-1},
$$

where $r$ is the rate of interest of the weighted average cost of capital (in this study, it is assumed as $11 \%$ ), and $i$ is the investment life (normally the life cycle of the power supply system). Table 1 indicates the competitive analysis of different mode of power supply system based on per unit generation cost of electricity ${ }^{32}$.

It is more realistic and appropriate to estimate the per unit generation cost for a particular area using society's cost of electricity (SCOE). In case of SCOE, the environmental and social benefits are included with the per unit generation to evaluate the generation cost and the impact of power generation on the society ${ }^{32}$.

$$
\begin{aligned}
& \text { SCOE = LCOE + cost of climate change damage } \\
& + \text { cost of air pollution damage } \\
& + \text { system integration costs. }
\end{aligned}
$$

The calculation of SCOE is based on available data and detailed experiments related to environmental effect are required.

The diesel generator is a good option for distributed generation system as it has a wide range of capacity from a few kilowatts to megawatts, with little overnight cost. However, the per unit generation cost is high compared to wind and biomass-based distributed generation system and its environmental effect also increases the SCOE compared to the other distributed generation systems. Among the power supply system using solar PV and solar thermal, the former process of generation of electricity is more effective because of less overnight cost, less per unit generation cost. Moreover, it has also the ability to construct in different generating capacity easily. To reduce the per unit generation cost in the latter system the capacity should increase, which introduces the concentrated grid connected system. In case of the onshore wind and offshore wind, the former has less overnight cost, less maintenance cost and less per unit generation cost. Normally, wind speed fluctuates less at offshore than onshore, which indicates more reliable generation of electricity is possible at offshore as compared to onshore. It also reduces the mechanical and electrical stresses for supporting equipments of generation of electricity using wind energy. The biomass-based distributed generation system provides minimum per unit generation cost compared to the other distributed generation systems, but SCOE is high due to the production of harmful gases during generation of electricity. The other problem related to the biomass-based distributed generation system is the large capacity to minimize generation cost, and the cost related to maintain the quality of biomass during winter and the rainy season. In case of tidal and wave energybased distributed generation system, the former has less per unit generation cost compared to the latter. The size of the generation system in case of wave energy is huge, which is similar to the concentrated distributed generation system. The battery is the inevitable unit of the distributed generation system which stores the surplus generated energy and supplies it to the consumer, whenever the primary source of energy is lacking.

From an overview of the different distributed generation systems, the SCOE is found to be higher in case of diesel and biomass-based distributed generation system as this contaminates our environment during generation of electricity. All the other distributed generation systems are environmentally-friendly. The problem related to renewable energy resources are their intermittent nature which vary with time. By analysing the available data, solar energy is found to be most promising energy source. The available technology also supports electricity generation successfully but the problem related to solar energy is its highly intermittent nature. The energy is not only unavailable at night, but also during the monsoon. The intermittency increases the size of the storage devices and hence the cost increases. The intermittency of wind energy 


\section{RESEARCH COMMUNICATIONS}

is lower in the Sagar Island but wind speed is moderate, which indicates lower energy output with a high-capacity wind turbine. The biomass energy sources are also promising according to availability, but a problem arises to maintain the quality of biomass during monsoon which introduces high cost and large energy storage devices. In case of tidal and wave energy sources, intermittency does not have made effect much due to seasonal variation, but the wave energy needs a lot of time and huge cost to generate electricity compared to the tidal energy. The blue energy and OTEC are new technologies in the generation of electricity. Both the systems introduce huge overnight cost. To generate electricity efficiently using these technologies and make it feasible at the utility level, more research work is to be focused.

The various energy sources in a particular rural area of Sagar Island have been discussed here. Due to inconsistency in different renewable energy sources, the electricity generation from a single renewable energy source is not reliable. The battery bank maintains the required reliability of such a energy source. Due to the poor life cycle and high maintenance cost, the overall cost of electricity generation increases. Instead of a large battery bank, the hybrid system may be introduced in Sagar Island to maintain reliability using solar- and wind-based hybrid system to generate electricity, as wind energy does not vary during monsoon. The biomass-wind-based distributed generation system can also be used, but the biomass-based electricity generation is harmful to the environment. At present, the generation of electricity using tidal energy sources is higher, but in future due to improved technology the per unit generation cost may reduce and the tidal-wind hybrid system may be utilized for generation of electricity.

1. http://www.cea.nic.in/reports/monthly/executivesummary/2017/exe summary-02.pdf

2. http://powermin.nic.in/en/content/power-sector-glance-all-india.

3. Mitra, I., Optimum Utilization of Renewable Energy for Electrification of Small Islands in Developing Countries, Kassel University Press, Kassel, Germany, 2009.

4. Mitra, I., A renewable island life: electricity from renewables on small islands. Refocus, 2006, 7(6), 38-41.

5. Lanfranchi, M. and Giannetto, C., A feasibility study for a project of alternative energy production in an Agritourism business in Sicily. Int. J. Environ. Stud., 2017, 75(2), 334-342.

6. Benli, H., Potential of renewable energy in electrical energy production and sustainable energy development of Turkey: performance and policies. Renew. Energy, 50, 2013, 33-46.

7. Shafiullah, G. M., Amanullah, M. T. O., Shawkat Ali, A. B. M. Dennis Jarvis, D. and Wolfs, P., Prospects of renewable energy - a feasibility study in the Australian context. Renew. Energy, 2012, 39(1), 183-197.

8. Beluco, A., Benevit, M., Gewehr, A. and Silva J., Subtle influence of the Weibull shape parameter on homer optimization space of a wind diesel hybrid gen set for use in southern Brazil. J. Power Energy Eng., 2016, 4, 38-48.

9. Ramdhane, I. B. et al., Optimization of electrical production of a hybrid system (solar, diesel and storage) pilot using HOMER in
Biret, southern coast of Mauritania. Int. J. Phys. Sci., 2017, 12, 211-223.

10. Sen, R. and Bhattacharyya, S. C., Off-grid electricity generation with renewable energy technologies in India: an application of HOMER. Renew. Energy, 2014, 62, 388-398.

11. Moharil, R. M. and Kulkarni, P. S., A case study of solar photovoltaic power system at Sagardeep Island, India. Renew. Sustain. Energ. Rev., 2009, 13(3), 673-681.

12. Hiremath, R. B. et al., Decentralised renewable energy: scope, relevance and applications in the Indian context. Energ. Sustain. Develop., 2009, 13(1), 4-10.

13. Mondal, M. and Mandal, S., Remote village electrification through renewable solar energy: a case study of Sagar Island, West Bengal, India. Int. J. Eng. Sci., 2013, 2(1), 201-205.

14. Palit, D. and Sarangi, G. K., Renewable energy based mini-grids for enhancing electricity access: experiences and lessons from India. In International Conference and Utility Exhibition on Green Energy for Sustainable Development (ICUE 2014), Thailand, 2014, pp. 1-8.

15. Roy, P. C., Majumder, A. and Chakraborty, N., Optimization of a stand-alone solar PV-Wind-DG hybrid system for distributed power generation at Sagar Island. AIP Conference Proceedings, 2010, 1298(1), 260-265.

16. http://www.surveykshan.gov.in/ (retrieved on 17 May 2017).

17. Mandal, S., Choudhury, B. U., Mondal, M. and Bej, S., Trend analysis of weather variables in Sagar Island, West Bengal, India: a longterm perspective (1982-2010). Curr. Sci., 2013, 105(7), 947-953.

18. Seelam, P. K. and Giribabu, L., Recent advances in perovskitebased solar cells. Curr. Sci., 2016, 111(7), 1173-1181.

19. Surface meteorology and solar energy-NASA. (n.d.). https://eosweb.larc.nasa.gov/sse/ (retrieved on 19 May 2017).

20. Tummala, A., Velamati, R. K., Sinha D. K., Indraja, V. and Krishna, V. H., A review on small scale wind turbines. Renew. Sustain. Energ. Rev., 2016, 56, 1351-1371.

21. Gebreegziabhera, T., Oyedunb, A. O., Lukb H. T., Lamb, T. Y. G., Zhangb, Y. and Huib, C. W., Design and optimization of biomass power plant. Chem. Eng. Res. Desig., 2014, 9(2), 1412-1427.

22. Nixon J. D., Dey, P. K. and Davies, P. A., The feasibility of hybrid solar-biomass power plants in India. Energy, 2012, 46, 541-554.

23. Deshmukh, S. P. and Goswami, P., An overview of ocean energy in the world and its potential in India. Water Energ. Int., 2016, 59(5), $62-68$.

24. https://www.tide-forecast.com/locations/Sagar-IslandIndia/tides/latest (retrieved on 17 October 2017).

25. Sharma, R. C. and Sharma, N., Energy from the ocean and scope of its utilization in India. Int. J. Environ. Eng. Manage., 2013, 4(4), 397-404

26. Ocean wave energy resources in National Data Buoy Centre, USA, (n.d.). http://www.ndbc.noaa.gov/ (retrieved on 20 October 2017).

27. Emdadi, A. E. A., Afshar, O. A. and Emami, Y., Electricity generation by the Ocean thermal energy. Energy Proc., 2011, 12, 936-943.

28. Fujita, R. et al., Revisiting ocean thermal energy conversion. Mar. Pol., 2012, 36(2), 463-465.

29. Ross, R. and Krijgsman, J., New ionomer membranes for blue energy - making water trees useful. In International Conference on Future Power Systems, India, 2004, vol. 2, pp. 780-783.

30. Roche, M. Y., Comparison of costs of electricity generation in Nigeria - Technical Report, Abuja, Nigeria, 2017.

31. Kulkarni, P. S., Patil, A., Kothari, S., Pohnekar, E., Bharambe, K. and Doshi, K., Captive power generation. In National Power Systems Conference (NPSC), Chennai, 2004, pp. 528-531.

32. Annual Energy Outlook 2016 - Energy Information Administration; https://www.eia.gov/outlooks/aeo/pdf/0383(2016).pdf

Received 12 July 2017; revised accepted 13 February 2019

doi: $10.18520 / \mathrm{cs} / \mathrm{v} 116 / \mathrm{i} 8 / 1381-1386$ 